Artigo

\title{
"Eran estos libros no como los nuestros": crónicas de un encuentro bibliográfico entre dos mundos
}

\section{"These books were not like ours": chronicles of a bibliographic encounter between two worlds}

\author{
Marina Garone Gravier' ${ }^{(\mathbb{D}}$ \\ ' Universidad Nacional Autónoma de México, Instituto de Investigaciones Bibliográficas, \\ Ciudad de México, México
}

\section{RESUMEN}

El presente artículo pretende precisar las características de lo que se entendía por "libro y escritura" durante los procesos culturales, políticos y sociales de la conquista de América; esto visto a través de la mirada extranjera que comparó los usuarios, soportes, estructuras materiales y sistemas de notación indígena con el alfabeto latino y los libros europeos, lo que permitirá obtener un breve panorama del intercambio cultural.

Palabras clave: Conquista de América; Crónicas; Bibliografía; Libros; Códices

\section{ABSTRACT}

This article tries to specify the characteristics of what was understood by "book and writing" during the cultural, political and social processes of the conquest of America; This seen through the foreign gaze that compared the users, supports, material structures and indigenous notation systems with the Latin alphabet and European books, which will allow us to obtain a brief overview of cultural exchange.

Keywords: Conquest of America; Chronicles; Bibliography; Books; Codices

\section{PRESENTACIÓN}

¿Qué es un libro? Es una frase que admite numerosas respuestas, y sobre todo si se plantea en el eje diacrónico cuando uno se propone mirar al pasado y llegar al presente, en otras palabras, vale la pena señalar que lo que se ha entendido por libro 
no ha sido una definición estable a través del tiempo y mucho menos en distintas culturas. Si tomamos como base el horizonte cultural, político y social de la conquista de América, el objeto libro y su definición activó diversas reflexiones que, a la postre, determinaron tipos y variedades de objetuales materiales, modelos de producción y organización laboral y transmisión textual de la cultura escrita, así como diversas concepciones en torno del negocio tipográfico, mercado librario y la circulación de las ideas que tuvo una fuerte incidencia en las autoimágenes de las comunidades americanas y también en la forma que fueron estudiadas, conocidas y divulgadas esas sociedades por comunidades no americanas.

Si bien para varias de las culturas prehispánicas los binomios lengua-escritura e historia-libro y las dobles articulaciones fueron ciertos, no lo fueron para todas las naciones y pueblos originarios, pero más allá de que no todos los grupos humanos americanos contaron con sistemas de registros visuales de la lengua, en los casos en los que sí existieron registros, los cuestionamientos que se activaron fueron de orden epistemológico: ¿son esos libros verdaderos?, por su forma y su contenido ¿son realmente libros?, en una palabra se puso en crisis el conjunto de criterios de validación y el estatuto de las escrituras y los libros americanos. La "materialidad", en todas sus dimensiones, jugó un rol determinante en la compresión de los artefactos culturales de América, todos los artefactos, especialmente aquellos que tenían atributos o propiedades como "entidades portadoras de historias" - por ejemplo, esculturas, pinturas, e inclusive libros - no estuvieron excluidos de las valoraciones de los conquistadores. Así de los libros, mapas, lienzos y pinturas locales se analizaron detenidamente los soportes, las estructuras y los funcionamientos físicos y morfológico, el tipo de narrativas que eran susceptibles de albergar, así como los sistemas de signos mismos, los productores y lectores, y los espacios para su resguardo.

Las opiniones, descripciones y valoraciones quedaron plasmadas en numerosos registros, para aproximarnos a ellos haré un recuento cronológico de algunas de las citas más relevantes, poniendo en primer lugar las que se refieren al ámbito americano, de manera general, y luego las que se refieren específicamente a la Nueva España. Aunque 
sea obvio señalarlo, puntualizo que la relación de obras que he tomado en cuenta para este boceto panorámico no es exhaustiva, mas permite identificar con mucha nitidez algunas variables y elementos constantes en las opiniones sobre lo que fue observado en torno al mundo del libro prehispánico tras en contacto de dos mundos.

\section{METODÓLOGÍA}

2021 será recordado, entre varios hechos más, por la conmemoración del quinto centenario de la caída de México-Tenochtilán, la antigua capital del imperio mexica, en manos del imperio español. Ese hecho que encierra el epítome de un proceso de conquista y destrucción es también el inicio de un proceso de encuentro, aproximación y amalgama intercultural en el cual los libros y los sistemas de escritura cumplieron un papel muy relevante. En tanto dispositivo gráficos y artefactos tecnológicos, los libros pueden ser considerados como uno de los rasgos de producción comunicativa que identifica a las sociedades que los producen y consumen. La presencia y ausencia de libros y escrituras en un pueblo fue, durante mucho tiempo, uno de los elementos que alentó distinciones y clasificaciones de los grupos humanos, definiciones como "civilizados" o "bárbaros" se sustentaron en gran medida por la existencia o inexistencia de documentos escritos.

Por la fuerza que ese rasgo cultural cobró en los procesos de conquista y dominio, es comprensible la sorpresa que los conquistadores españoles experimentaron al identificar entre los grupos mesoamericanos objetos materiales que compartían ciertas características similares con lo que ellos definían y entendían por "libros y escrituras". Sin embargo, es justamente en el modo en los libros americanos fueron mirados y descritos por los conquistadores que es posible encontrar una algunas de las claves epistémicas para identificar qué se entendió en el contexto de contacto por libro y escritura.

Considerando lo anterior es importante ubicar el panorama en el que se inscribe este trabajo: se parte de una pregunta absolutamente vigente y pertinente no solo para quienes estudian el mundo del libro y la edición sino también para quienes estudian los 
procesos de comunicación intercultural. Las referencias y crónicas sobre los libros y escrituras prehispánicas son hoy uno de los elementos que permiten reflexionar sobre las culturas y sus modelos comunicativos.

Las coordenadas espacio temporales en que se inscribe este trabajo se sitúan entre finales del siglo XV y el siglo XVI, es decir se desarrollan de modo paralelo a la conquista de América y la caída de México-Tenochtilán y se prolongan en el siglo XVI. Las fuentes de las que me valdré son un racimo de referencias provenientes de manuscritos e impresos, crónicas en su inmensa mayoría, que recogen las descripciones y opiniones de los que vinieron "allende el mar": conquistadores de los espacios terrenales y celestiales: militares como frailes. El conjunto de referencias de esas "miradas europeas" se usará como un "dispositivo especular", es decir, aquellas opiniones me permitirán identificar algunos de los ejes en los que se planteó una fuerte discusión en la que los binomios lengua-escritura e historia-libro, se daban por sentados.

Considerando lo anterior, he seleccionado una serie de referencias provenientes en su inmensa mayoría de crónicas, en las que existen descripciones y opiniones sobre los libros americanos. Los autores de dichos textos fueron militares, funcionarios reales y evangelizadores, encargados de la empresa de conquista o que dieron cuenta de ella a pensar de no haber participado de manera directa. Analizaremos de esas citas cómo se refirieron a los libros y sistemas de registro con el objetivo final de poner en evidencia las claves de "lo visto y no visto" en relación con esos artefactos prehispánicos.

\section{DE LA DESCRIPCIÓN MATERIAL A LA COMPARACIÓN DE SISTEMAS DE ESCRITURA: LAS OPINIONES DE PEDRO MÁRTIR DE ANGLERÍA}

Quizá unos de los registros más tempranos e interesantes de la descripción de rasgos culturales de los grupos indígenas de América fueron los proporcionados por Pedro Mártir de Anglería que pueden leerse en su obra Décadas de Orbe Novo o Décadas del Nuevo Mundo. La obra escrita en latín por este autor italiano está conformada por ocho partes, y cada una de las ellas abarca una década, y a la vez cada una está subdivida en diez libros. La escribió 
entre 1494 y 1526, en 1511 se publicó en Sevilla la primera década, cinco años después se publicó en Alcalá de Henares la versión oficial de las tres primeras décadas, pero no fue sino hasta 1550, luego del fallecimiento del autor, que se publicó la obra completa.

Aunque parezca una contradicción, Anglería escribió de un lugar que nunca conoció ya que no llegó a pisar América, pero se nutrió de los relatos y comentarios de los descubridores españoles a los que tuvo fácil acceso por estar en las cortes de los Reyes Católicos, Juana la Loca y Carlos V. Entre los personajes que conoció y de quienes tomó referencias para escribir se encuentran Cristóbal Colón, Alonso de Ojeda, Américo Vespucio, Fernando de Magallanes y Hernán Cortés.

Un dato relevante para entender la capacidad de Anglería de interpretar referentes multiculturales y la forma de evaluar manifestaciones escritas en otros sistemas distintos al latino es que formó parte de las campañas que Î́ñigo López de Mendoza y Quiñones, conde de Tendilla, emprendió en Andalucía contra el reino nazarí, contexto bélico en el cual conoció a Colón. Como contraprestación por los servicios militares que prestó en el sur de España, y como miembro de la corte de los reyes católicos, participó en una comitiva de mediación a Egipto, experiencia diplomática que le permitió escribir el libro Legatio Babylonica, impreso por Jacobo Cromberger en Sevilla en 1511. Tras la muerte de la reina Isabel, de quien llegó a ser capellán, permaneció en la corte hasta convertirse en consejero de confianza de Carlos, fue en ese contexto que Anglería comenzó a tener nombramientos vinculados con América: cronista real y obispo de Jamaica. Anglería fue cronista de Indias desde 1520 y participó en el Consejo de Indias entre 1520 y 1526 es decir que le tocó vivir el momento de la caída de la capital de imperio mexica a manos españolas, pero además realizó tareas diplomáticas para la corte de los reyes católicos en Egipto.

Los trabajos militares y diplomáticos ante culturas con sistemas de registro escrito distintos al alfabeto latino posiblemente tuvieron alguna influencia en el modo de ver y describir que usó al referirse a las escrituras y documentos americanos. Justamente entre los elementos a los que de Anglería dedicó especial atención no solamente estuvo el papel, del cual explicaba el procedimiento para su elaboración y el funcionamiento de los libros 
prehispánicos, sino también las "letras" de los indígenas y el contenido de los documentos, como veremos a continuación:

"llevamos dicho que esta gente posee libros, y trajeron muchos, junto con los demás dones, estos nuevos colonos de Coluacán y los procuradores y mensajeros. En lo que ellos escriben son unas hojas de cierta delgada corteza interior de los árboles [...]. Cuando están blandas, les dan la forma que quieren y la extienden a su arbitrio, y luego de endurecida la embetunan, se supone que con yeso [...]. Es de creer que [...] De tablillas de higuera se hacen los libros que los administradores de las casas grandes llevan consigo por los mercados, y con un punzón de metal apuntan lo que compran para borrarlo cuando ya no lo han trasladado a sus cuadernos de cuentas.

No solamente encuadernan los libros, sino que también extienden a lo largo esa materia hasta muchos codos, y la reducen a partes cuadradas, no sueltas, sino tan unidas con un betún resistente y tan flexible, que, en comparación de las tablas de madera, parece que han salido de manos de hábil encuadernador. Por dónde quiera que se mire el libro abierto, se presentan dos caras escritas; aparecen dos páginas, y se ocultan bajo ellas otras dos como no se extienda a lo largo, pues debajo de un folio hay otros muchos folios unidos.

Los caracteres son muy diferentes de los nuestros; dados, ganchos, lazos, tiras y estrellas y otras figuras, escritas en línea como lo hacemos nosotros; se parecen mucho a las formas egipcias (de escribir). Entre líneas hay trazadas figuras de hombres y animales, principalmente de los reyes y magnates, por lo cual es de creer que están allí escritos los hechos de los antepasados de cada rey, como vemos que se hace en nuestro tiempo, que muchas veces en las historias generales y en los códices fabulosos los impresores intercalan las figuras de los que hicieron lo que allí se cuenta, para estimular a los que quieran comprarlos.

También las tablas de arriba (las cubiertas) las arreglan agradablemente de madera: cerrados esos libros, parece que no son diferentes de los nuestros. También se cree que escriben en sus libros las leyes, los sacrificios, ceremonias, ritos, anotaciones astronómicas y ciertos cómputos, y los modos y tiempos de sembrar. (1530, p. 335-336).

\section{INVALIDEZ DE LA ESCRITURA DEL OTRO: EL JUICIO DE GONZALO FERNÁNDEZ DE OVIEDO VALDÉS}

La segunda cita que incluyo en este recuento es de Gonzalo Fernández de Oviedo Valdés, un militar nombrado por el emperador Carlos V como primer cronista de las Indias, 
ocupó además el cargo de gobernador de Santo Domingo y La Española. Se había criado en el entorno humanístico y erudito de un familiar cercano del rey Fernando el Católico, hecho que le permitió tomar contacto, por ejemplo, con los hijos de Colón y más tarde visitar y tener vinculación con los círculos ducales de Milán, Roma y Nápoles. De regreso a España, se reintegró a la corte de Fernando y ejerció labores notariales tanto en el ámbito público como inquisitorial. En la década de 1510 hizo un primer viaje a América, y luego de una segunda estancia en el nuevo mundo, publicó el Sumario de la natural historia de las Indias (1526), que precedió a su famosa Historia general y natural de las Indias, islas y tierra firme del mar océano. La primera parte de esa obra se imprimió en 1535 y la segunda en Valladolid, pero quedó interrumpida por la muerte del autor en 1557. La obra solo vio la luz en forma completa en el siglo XIX.

Justamente en su historia indiana, Fernández de Oviedo señalaba que los indígenas:

“Tenían libros de pergamino, que hacían de los cueros de venado... y en aquestos tenían pintados sus caracteres e figuras de tinta roja y negra de tal manera que aunque no eran lecturas ni escritura significaban e se entendían por ellas todo lo que querían muy claramente...." (https://www.mexicodesconocido.com.mx/codices-prehispanicos-mexico.html)

Si bien la cita es muy breve por los elementos materiales, cromáticos y la consideración de los signos, nos hace pensar que su capacitación en tareas de notario cobró especial relevancia para la síntesis y elocuencia de su descripción.

\section{IMÁGENES QUE NO SON LETRAS VERDADERAS: LAS IDEAS DE JOSÉ DE ACOSTA}

Entre los autores que analizaremos, el que hace el planteamiento más detallado de la diferencia entre las letras "verdaderas" y los signos de los indígenas de América es el jesuita José de Acosta. Oriundo de una familia burguesa de Medina del Campo, Acosta y la mayoría de sus hermanos siguieron una vida religiosa en la orden jesuita. Su formación intelectual en filosofía, teología y ciencias naturales posibilitaron que pronto ejerciera labores docentes en diversos destinos, y eso mismo los impulsó a solicitar un permiso para 
pasar a América. Llegó primero a la Isla La Española y en 1571 se trasladó a Perú, donde llegó a ocupar el cargo de provincial de la orden ese país. Durante su estancia en ese país acompañó al virrey Francisco de Toledo en sus largos periplos por el territorio. Parte de sus tareas se encaminaron a la fundación de colegios de la Compañía en diversas zonas del virreinato del Perú, y también ocupó la cátedra de teología en la Universidad de San Marcos en Lima. En 1576 fue designado provincial de la Compañía de Jesús, la carrera administrativa dentro de la compañía lo puso en una posición singular y le permitió llevar a cabo una destacada labor en el III Concilio Católico Limense. Fue en ese contexto conciliar que, entre otras cosas, se discutieron las estrategias y medios para una labor evangélica más efectiva de los grupos indígenas del Perú, y varias de las consignas emanadas de esa reunión estuvieron encaminadas a la escritura y producción de catecismos en quechua y aymara, tarea en la que Acosta tuvo una participación directa. Acosta escribió varios libros sobre tema americano y la Historia Natural y Moral de las Indias, es quizá uno de los más conocidos. Es justamente en esa obra en la que el jesuita asegura que:

las letras se inventaron para referir y significar inmediatamente las palabras que pronunciamos, así las mismas palabras y vocablos, según el filósofo [Aristóteles], son señales inmediatamente de los conceptos y pensamientos del hombre. Y lo uno y lo otro (digo las letras y las voces), se ordenaron para dar a entender las cosas: las voces a los presentes; las letras a los ausentes y futuro. Las señales que no se ordenan de próximo a significar palabras sino cosas, no se llaman ni son en realidad de verdad letras, aunque estén escritas, así como una imagen del sol pintada no se puede decir que es escritura o letras del sol sino pintura. [...] Estas tales señales no se dicen ni son propiamente letras ni escritura, sino cifras o memoriales. [...] ninguna nación de indios que se ha descubierto en nuestros tiempos, usa de letras ni escritura, sino de las otras dos maneras, que son imágenes o figuras, y entiendo esto no sólo de los indios del Pirú (sic) y de la Nueva España, sino también de los japones y chinas. (1590).

Esta referencia sudamericana se vincula también con menciones que hemos encontrado en los preliminares de los libros novohispanos, en los que algunos autores hacen continua mención a la dispersión de las setenta lenguas ocurrida tras el colapso de la torre de Babel, argumento que en general emplean para explicarse a sí mismos y comprender la magnitud de la diversidad lingüística americana. En algunos casos 
extremos ese argumento intenta establecer la relación parental de las lenguas del Nuevo Mundo con algunas de las del viejo mundo, sin embargo, algunos, como el propio Acosta, religiosos desestiman esas explicaciones filogenéticas.

Las valoraciones sobre las lenguas indígenas americanas se dieron de forma paralela a la discusión acerca de las lenguas vernáculas europeas, y en estas discusiones España desempeñó un papel importante por ser allí donde se publicó en 1492 la primera gramática contemporánea del castellano. Con este hecho se inicia el proceso de igualación de las lenguas vernáculas al latín y el griego, proceso que se verá reforzado en el Concilio de Trento con las normativas tocantes a la producción de catecismos en las lenguas comunes. Muy pronto se comenzarían a desarrollar gramáticas y vocabularios de las lenguas indígenas americanas, inclusive en algunos casos mucho antes que las gramáticas para la mayoría de las lenguas europeas modernas. Sin embargo, las opiniones favorables sobre las lenguas indígenas no se mantuvieron constantes durante el periodo colonial, y estuvieron en consonancia con los prejuicios y estigmas con que se trataba a los propios indígenas.

Parte de estos prejuicios sobre la lengua y cultura indígenas se alimentaban por la falsa opinión de que los pueblos americanos carecían completamente de sistemas de registros escritos. Asimismo, y en los casos en que existían los registros y libros (los códices), se cuestionaba la naturaleza de los mismos como portadores y contenedores de información.

\section{LOS USOS DE LOS LIBROS EN LA OPINIÓN DE FRAY DIEGO DE LANDA}

El cuarto autor que dejó testimonio de su sorpresa y fascinación por los libros prehispánicos fue el franciscano Diego de Landa. De Landa nació en Guadalajara, España, donde tomó los hábitos seráficos, y más tarde formó parte del grupo liderado por fray Nicolás de Albalete para misionar en la Provincia franciscana de Yucatán desde finales de la década de 1540. Al parecer su facilidad para aprender el idioma maya, le permitió contar con el permiso de sus superiores para predicar en amplias extensiones de esa península y fundar pueblos para congregar a los nativos. Tuvo varios cargos religiosos en el capítulo 
de la Orden en esa región y en el ejercicio de sus labores llegó a tener confrontaciones con los grupos de civiles españoles y también con el clero secular.

Las tensiones que tuvo que enfrentar de Landa se dieron en la década de 1560, casi al mismo tiempo que las provincias de Yucatán y Tabasco se adscribían administrativa y civilmente hablando a la Audiencia de México y durante el periodo en que se generó primero la integración de las provincias franciscanas de Yucatán y Guatemala y más tarde la separación definitiva en dos provincias distintas: la de San José y la del Santísimo Nombre de Jesús. En el contexto de erección y consolidación de la provincia religiosa de Yucatán tuvo lugar en 1562 la localización de evidencias de rituales indígenas en Maní, los hechos fueron denunciados ante las autoridades civiles y religiosas españolas, y a partir de ellas de Landa tomó especial acción. Es a partir del auto de fe de Maní realizado en la península de Yucatán, el 12 de julio de 1562, Landa destruyó innumerables códices mayas, hecho por el que es recordado como el mayor pirómano de documentos prehispánicos. A diferencia de la imagen y los testimonios que se tienen de sus compañeros de orden, él llevó a cabo procesos confesionales y de extirpación de idolatrías especialmente violentos en los cuáles se practicó además la recolección y quema de pinturas y códices. El radicalismo de sus acciones le valieron ser relevado del cargo por parte de Francisco de Toral, su superior, quien lo hizo regresar a Europa. No fue sino hasta la muerte de aquél que pudo regresar a la península de Yucatán de la cual llegó a ser segundo Obispo entre 1572 a 1579.

Su fanatismo no le impidió expresar la fascinación y curiosidad que sentía por los objetos prehispánicos, que se hacen evidentes en las opiniones sobre la enseñanza de la escritura de los libros de rituales, adivinanzas y calendarios. Sobre este punto, explica Landa en Relación de las cosas de Yucatán:

los de Yucatán fueron tan curiosos en las cosas de la religión, en las cosas del gobierno y que tenían un gran sacerdote que llamaron Ah Kin May [...] que proveían de sacerdotes a los pueblos cuando faltaban, examinándolos en sus ciencias y ceremonias [...] y proveían de sus libros; (además) atendían al servicio de los tempos y a enseñar sus ciencias y escribir libros de ellas. Que enseñaban a los hijos de los otros sacerdotes y a los hijos segundos de los señores que les llevaban para esto desde niños [...]. Que las ciencias que enseñaban eran la cuenta de los años, meses y días, las fiestas y ceremonias, [...], sus maneras de adivinar, remedios para los males, las antigüedades, leer 
y escribir con sus letras y caracteres en los cuales escribían con figuras que representaban las escrituras. Que escribían sus libros en una hoja larga doblada, con pliegues que se venia a cerrar toda entre dos tablas que hacían muy galanas, y que escribían de una parte y de otra a columnas, según eran los pliegues; y que este papel lo hacían de las raíces de un árbol y que le daban un lustre blanco en que se podía escribir bien, y que algunos señores principales sabían de estas ciencias por curiosidad, y que por esto eran más estimados aunque no las usaban en público". "[A los] Muertos, [...] enterrábanlos dentro de sus casas o a las espaldas de ellas, echándoles en la sepultura algunos de sus ídolos; y si era sacerdote, algunos de sus libros. (1566).

\section{LETRAS COMO FIGURAS: LAS RECREACIONES DE FRANCISCO LÓPEZ DE GÓMARA}

A continuación, vamos a referirnos a un par de cronistas de la conquista, Francisco López de Gómara y Bernal Díaz del Castillo, ya que en cierta medida en sus obras hay un diálogo o dicho de otro modo, desmentidos o puntos de vistas complementarios sobre ciertos hechos y datos. Sin embargo, a diferencia del segundo, quien participó en tres expediciones militares al nuevo mundo, López de Gómara nunca pisó América.

López nació hacia 1511, se formó en Soria y, ya ordenado sacerdote, se trasladó a Roma donde conoció a Hernán Cortés. Fue por ese encuentro que llegó a ser secretario y capellán del militar, cercanía que, junto con su formación humanística, lo impulsó a escribir la Historia de la conquista de México, que pronto se convirtió en una obra numerosas veces editada. Al igual que lo vimos en Ascosta, López será uno de los autores que dirá que los sistemas de notación indígena no cuentan con un estatuto equivalente al del alfabeto latino, esas opiniones se pueden leer en el siguiente fragmento de La conquista de México:

No se han hallado letras hasta hoy en día en las Indias, que no es pequeña consideración; solamente hay en Nueva España una especie de figuras que sirven de letras, con las cuales anotan y entienden toda cosa cualquiera y conservan el recuerdo y antigüedades. Se asemejan mucho a los jeroglíficos de Egipto, mas no encubren tanto el sentido, según he oído; aunque ni debe ni puede ser menos. Estas figuras que usan los mexicanos como letras son grandes; y así ocupan mucho. Las tallan en piedra y madera; las pintan en paredes, y en papel que hacen de algodón y hojas de amate. Los libros son grandes cogidos como pieza de paño, y escritos por ambos lados; los hay también arrollados como piezas de jerga. No pronuncian la b, g, r, s, y así 
emplean mucho la p, c, l, x; esto es la lengua mexicana y náhuatl, que es la mejor, más copiosa y más extendida que hay en la Nueva España y que emplean las figuras. (1552).

Al igual que de Anglería, López de Gómara compara las producciones americanas con las egipcias, pero reconoce que son más "transparentes" en su sentido, asimismo distingue el tamaño de los signos, comparando este atributo visual del sistema con el alfabeto latino; finalmente habla de los soportes de escritura y de la fonología de la lengua náhuatl.

\section{TIPOLOGÍA DOCUMENTAL: LO QUE CUENTA BERNAL DÍAZ DEL CASTILLO}

Bernal Díaz del Castillo inició sus travesías militares en América con apenas 20 años, primero en Cuba, y más tarde participando en expediciones a Yucatán, Veracruz, MéxicoTenochtitlán, junto a Cortés, y finalmente Guatemala y Honduras. Para obtener la retribución por los servicios militares prestados a la Corona, realizó varios viajes de gestión a España, entre las décadas de 1540 y 1550, periodo en el cual fue dando forma al manuscrito en el que narraría los hechos de la conquista mexicana. Los estudiosos de Díaz del Castillo coinciden en que 1568 fue la fecha de la conclusión de Historia verdadera de la conquista de la Nueva España, una copia llegó a España en 1575, y sirvió de base a la primera edición impresa de la obra que fue publicada póstumamente en 1632. Lo cierto es que sobre la persona y participación de Bernal en las campañas de América hay no pocas dudas, ya que no se lo menciona ni figuran en algunos documentos importantes de la época, por ejemplo las cartas de Cortés. Sin embargo, la obra de Bernal existe y se publicó; es justo en el contexto de las travesías militares para la conquista capital mexicana que, al hablar de la avanzada que había hecho el conquistador Pedro de Alvarado, Bernal refiere lo siguiente: “[...] Y hallamos las casas de ídolos y sacrificaderos [...], y plumas de papagayos y muchos libros de su papel cogidos a dobleces, como a manera de paños de corte. [...]." (1632).

Cuando pasa a describir la persona de Montezuma dice:

[...] Acuérdome que era en aquel tiempo su mayordomo mayor un gran cacique, [...], y tenía cuenta de todas las rentas que le traían al Montezuma con sus libros, hechos de su papel, que se dice amal, y tenía destos libros una gran casa dellos. (BERNAL, 1632). 
Y sigue más adelante:

[...] En los libros de la renta de Montezuma mirábamos de dónde le traían los tributos del oro y dónde había minas y cacao y ropa de mantas, y de aquellas partes que veíamos en los libros y las cuentas que en ellos tenía Montezuma, que se lo traían, queríamos ir, [...] (BERNAL, 1632).

\section{ESCRITURAS CONFUSAS: LAS CONSIDERACIONES DE FRANCISCO CERVANTES DE SALAZAR}

Francisco Cervantes de Salazar es el último autor del que traeré citas para este trabajo. Toledano de nacimiento, pasó por la Universidad de Salamanca sin alcanzar título, más tarde ocupó algunos cargos en la Cancillería de Valladolid y el Consejo de Castilla. Sus trayectorias académicas en España son muy nebulosas, al decir de los estudiosos que se ocuparon de su figura como por ejemplo Agustín Millares Carlo. Arribó en la década de 1550 a Nueva España, se vinculó con la Real y Pontificia Universidad de México donde fue lector y, asimismo alcanzó el rango de dean de la Catedral de la Ciudad de México.

En el capítulo XIX del libro III de la Crónica de la Nueva España, Cervantes habla de un regalo que recibió Cortés, y comenta sobre el papel de los códices mexicas:

"Inviáronse con estas cosas algunos libros, cuyas letras eran como las que dice Artimidoro, giroglificas, de las cuales al principio usaron los egipcios. Eran figuras de hombres, de animales, árboles, hierbas, las cuales, pintadas, declaraban, como nosotros por nuestras letras, los conceptos de los que escrebían, aunque confusamente; eran estos libros, no como los nuestros, sino como rollos de papel engrudado, que descogidos daban a entender lo que contenían. Era este papel hecho de ciertas hojas de árboles; parece papel de estraza, aunque más liso y blanco". (CERVANTES).

\section{A MANERA DE CONCLUSIONES}

Como hemos podido leer a través de las citas presentadas, los cronistas describieron varios aspectos de la cultura escrita, a saber: 1) estructuras, 2) soportes, 3) sistema de escritura, 4) géneros editoriales, 5) usuarios y 6) espacio de resguardo. 
Cuadro 1 - Relación de fuentes documentales analizadas y aspectos de la cultura escrita y libraria descritas en ellas

\begin{tabular}{|c|c|c|c|c|c|c|c|c|c|c|}
\hline Cargo & Autor & Obra & Manuscrito & $\begin{array}{l}\text { Edición } \\
\text { impresa }\end{array}$ & Estructura & Suporte & $\begin{array}{l}\begin{array}{c}\text { Sistema de } \\
\text { escritura }\end{array} \\
\end{array}$ & $\begin{array}{l}\text { Género } \\
\text { escrito }\end{array}$ & Usuario & $\begin{array}{l}\text { Espacio de } \\
\text { reguardo }\end{array}$ \\
\hline $\begin{array}{c}\text { Eclesiástico y } \\
\text { miembro del } \\
\text { Consejo de } \\
\text { Indias }\end{array}$ & $\begin{array}{l}\text { Pedro Mártir } \\
\text { de Anglería }\end{array}$ & $\begin{array}{c}\text { Décadas de Orbe } \\
\text { Novo o Décadas del Nuevo } \\
\text { Mundo }\end{array}$ & $1494 \mathrm{y} 1526$ & $\begin{array}{l}1511 \text { (primera } \\
\text { década) } 1550 \\
\text { obra completa }\end{array}$ & $\mathrm{x}$ & $\mathrm{x}$ & $\mathrm{x}$ & $x$ & & \\
\hline \multirow{2}{*}{$\begin{array}{l}\text { Military } \\
\text { primer } \\
\text { cronista }\end{array}$} & \multirow{2}{*}{$\begin{array}{c}\text { Gonzalo } \\
\text { Fernández de } \\
\text { Oviedo } \\
\text { Valdés }\end{array}$} & \multirow{2}{*}{$\begin{array}{l}\text { Historia general y natural de } \\
\text { las Indias, islas y tierra firme } \\
\text { del mar océano }\end{array}$} & \multirow{2}{*}{1566} & $\begin{array}{l}1535 \\
\text { (1ra. P.) }\end{array}$ & & \multirow[b]{2}{*}{$\mathrm{x}$} & \multirow{2}{*}{$\mathrm{x}$} & & & \\
\hline & & & & $\begin{array}{c}1557 \\
\text { (2da. P.) }\end{array}$ & & & & & & \\
\hline Religioso & $\begin{array}{l}\text { José de } \\
\text { Acosta }\end{array}$ & $\begin{array}{l}\text { Historia Natural y Moral de } \\
\text { las Indias }\end{array}$ & & 1590 & & & $\mathrm{x}$ & & & \\
\hline Religioso & $\begin{array}{c}\text { Diego de } \\
\text { Landa }\end{array}$ & $\begin{array}{l}\text { Relación de las cosas de } \\
\text { Yucatán }\end{array}$ & 1566 & & $\mathrm{x}$ & $\mathrm{x}$ & $\mathrm{x}$ & $\mathrm{x}$ & $\mathrm{x}$ & \\
\hline $\begin{array}{l}\text { Cronistay } \\
\text { religioso }\end{array}$ & $\begin{array}{l}\text { Francisco } \\
\text { López de } \\
\text { Gómara } \\
\end{array}$ & La conquista de México & & 1552 & $\mathrm{x}$ & $\mathrm{x}$ & $\mathrm{x}$ & $x$ & & \\
\hline Militar & $\begin{array}{l}\text { Bernal Díaz } \\
\text { del Castillo }\end{array}$ & $\begin{array}{c}\text { Historia verdadera de la } \\
\text { conquista de la Nueva } \\
\text { España }\end{array}$ & 1568 & 1632 & $\mathrm{x}$ & & & $\mathrm{x}$ & & $\mathrm{x}$ \\
\hline $\begin{array}{l}\text { Cronistay } \\
\text { religioso }\end{array}$ & $\begin{array}{l}\text { Francisco } \\
\text { Cervantes de } \\
\text { Salazar }\end{array}$ & Crónica de la Nueva España & $(1557-1566 \ldots)$ & & $\mathrm{x}$ & $\mathrm{x}$ & $\mathrm{x}$ & & & \\
\hline
\end{tabular}

Fuente: Elaboración propia (2021).

Por volumen de menciones en las citas, los elementos que más llamaron la atención de los cronistas fueron: los sistemas de escritura, estructura y soportes librarios, es decir los internos de los libros, y en segundo lugar los tipos documentales o géneros escritos, usuarios y espacios de resguardo, es decir los relativos al significado, modalidades de uso y consumo. Asimismo, de Landa, Anglería y López de Gómora parecen haber sido los más prolíficos.

Sobre las estructuras se señalaron la gran longitud que alcanzaban algunos códices, que la forma en que esos documentos eran guardados eran en dobleces cuadrados, y que algunas veces se encuadernaban con tapas de madera, aunque también había códices con forma de rollos; que las hojas estaban unidas en sí con un betún, que se escribían en ambas caras y que los escribas organizaban la información en columnas y que las páginas se presentaban en bifolios. Respecto de los soportes la mayoría de los registros coinciden en que el papel se hacía una higuera, algunos señalaban la corteza interior de los árboles, otros las hojas y otros las raíces. Varios refieren que el papel de se parecía al de estraza, aunque más liso y encalado con blanco. Además del amate se usaron cueros de venado, y papel que hacen de algodón.

La descripción del sistema de escritura indica que los caracteres eran de mayor tamaño que las letras usuales en el alfabeto, que parecían dados, ganchos, lazos, tiras y estrellas y otras figuras, escritas de manera lineal, parecidas a las formas egipcias. Los observadores reconocían que los libros eran de ciertos géneros, en ellos se registraban 
historias, leyes, ceremonias, rituales, el cómputo de tiempo y la astronomía, historia de gobernantes, cuentas y administración.

Los usuarios mencionados son los sacerdotes y sus hijos, algunos gobernantes y sus hijos, y aunque no serían propiamente usuarios, se señaló también que los libros formaron parte del ajuar funerario de los sacerdotes. Y justamente en relación los usuarios y los géneros, los espacios de resguardo tienen cierta correspondencia: era los templos, y en una especie de "notaría", es decir un lugar donde se concentraba el registro de los tributos.

Para finalizar es necesario decir que trabajos futuros podrán incrementar el tipo y variedad de referencias y obras de los cronistas que hubieran dado opiniones o elaborado descripciones sobre los códices y las escrituras prehispánicas. Asimismo, se podrá profundizar en los registros indígenas en busca de pareceres sobre los libros de los europeos y el sistema de escritura con base en el alfabeto latino al que fueron paulatinamente enseñados a escribir y en el que se tradujeron sus idiomas escritos, de ese modo se tendría un panorama dialógico sobre las opiniones interculturales de cómo se vieron y entendieron los libros en el contexto de conquista, dominación y también de resistencia.

\section{REFERENCIAS}

\section{PRIMARIAS}

ACOSTA, José de, Historia Natural y moral de las Indias, Impreso en Sevilla en la casa de Juan de León, 1590. Disponible en:

http://www.memoriachilena.gob.cl/archivos2/pdfs/mc0014757.pdf.Texto completo disponible en: http://www.cervantesvirtual.com/obra-visor/historia-natural-y-moral-de-las-indias--0/html/. Acceso en: 27 abr. 2021.

ANGHIERA, Pietro Martire d', De orbe nouo Petri Martyris ab Angleria Mediolanensis protonotarij C[a]esaris senatoris decades, Compluti: Apud Michaele[m] d[e] Eguia, 1530, Collection John Carter Brown Library. Disponible en:

https://archive.org/details/deorbenouopetrim00angh. Acceso en: 27 abr. 2021.

ANGLERIA Mediolanen, Petri Martyris ab, Oratoris clarissimi, Fernandi \& Helisabeth Hispaniarum quondam regum à consilijs, De rebus oceanicis \& Orbe nouo decades tres: quibus quicquid de inuentis nuper terris traditum, nouarum rerum cupidum lectorem retinere possit, copiose, fideliter, eruditeq[ue] docetur. Eiusdem præterea legationis Babylonicæ libri tres: ubi præter oratorii muneris pulcherrimum exemplum etiam 
quicquid in uariarum gentium moribus \& institutis insigniter pr[a]eclarum uidit, que[m]q[ue] terra mariq[ue] acciderunt, omnia lectu mirè iucunda, genere dicendi politissimo traduntur, Legatio Babylonica; Basileae, apud loannem Bebelium, 1533. Disponible en: https://archive.org/details/petrimartyrisaba00angh. Acceso en: 27 abr. 2021.

CERVANTES de Salazar, Francisco, Crónica de la Nueva España. Transcripción disponible en: http://www.cervantesvirtual.com/obra-visor/cronica-de-la-nueva-espana--0/html/. Acceso en: 27 abr. 2021.

CERVANTES de Salazar, Francisco, Crónica de la Nueva España, su descripción, la calidad y temple de ella, la propiedad y naturaleza de los indios [Manuscrito], Biblioteca Nacional de España, Signatura: Mss/2011. Disponible en: http://bdh-rd.bne.es/viewer.vm?pid=d-3424433. Acceso en: 27 abr. 2021.

CÓDICES PREHISPÁNICOS: el invaluable legado sobre nuestro pasado. México Desconocido. México, No. 33 noviembre / diciembre 1999. Disponible en:

https://www.mexicodesconocido.com.mx/codices-prehispanicos-mexico.html. Acceso en: 27 abr. 2021.

DÍAZ del Castillo, Bernal, Historia verdadera de la conquista de la Nueva España; sacada a luz por el P.M.Fr. Alonso Remon ... del Orden de N. S. de la Merced, En Madrid: en la Emprenta del Reyno, Biblioteca Nacional de España, SignaturaR/5239. Disponible en:

http://bdh.bne.es/bnesearch/detalle/bdh0000012937. Acceso en: 27 abr. 2021.

FERNÁNDEZ de Oviedo, Gonzalo, Ouiedo de la natural hystoria de las Indias, En la cibdad de Toledo: a costas del autor ... por ... Remo[n] de Petras, 1526, Biblioteca Nacional de España. SignaturaR/3864. Disponible en: http://bdh.bne.es/bnesearch/detalle/bdh0000050339. Acceso en: 27 abr. 2021.

FERNNDEZ de Oviedo y Valds, Gonzalo, Historia general y natural de las Indias, islas y tierrafirme del mar oceano, Madrid, Impr. de la Real academia de la historia, 1851-55, perteneciente a la Collection The LuEsther T Mertz Library, the New York Botanical Garden. Disponible en: https://archive.org/details/historiageneraly01fern. Acceso en: 27 abr. 2021.

IOANNES Ruffus Foroliuiensis Archiep[iscop]us Co[n]sentin[us]: legat[us] apo. ad lectore[m] De orbe nouo decades, [Alcalá de Henares]: Impressæ in contubernio Arnaldi Guillelmi in illustri oppido Carpetanæ p[ro]ui[n]ciæ Com[p]luto quod uulgariter dicitur Alcala p[er]fectu[m] est Nonis Noue[m]bris An. 1516, John Carter Brown Library Collection. Disponible en:

https://archive.org/details/ioannesruffusfor00angh/page/n11/mode/2up. También se puede consultar en: http://www.cervantesvirtual.com/obra/p-martyris-angli-mediolanensis-opera-legatio-babylonica-occeani-decas-poemata-epigrammatal. Acceso en: 27 abr. 2021.

LÓPEZ de Gómara, Francisco, La conquista de Mexico [En Caragoça: 1553. A costa de Miguel Capila mercader de libros vezino de Caragoça]. Disponible en:

https://archive.org/details/laconquistademex00/pez/page/n9/mode/2up. Acceso en: 27 abr. 2021. 
LÓPEZ de Gómara, Francisco, La historia general de las Indias, y todo lo acaescido enellas dende que se ganaron hasta agora; y La conquista de Mexico, y dela Nueua España, En Anuers: Por Martin Nucio, 1554. Disponible en: https://archive.org/details/lahistoriagenera00lpez. Acceso en: 27 abr. 2021 y https://archive.org/details/lahistoriagenera00lpez 0. Acceso en: 27 abr. 2021.

\section{SECUNDARIAS}

BAUDOT, Georges. Utopía e historia en México. Los primeros cronistas de la civilización mexicana. (1520-1569), Madrid, Espasa Calpe, 1983.

ESCALANTE Gonzalbo, Pablo y al. Nueva Historia mínima de México ilustrada. México. El Colegio de México: SEP, 2012.

GONZÁLEZ Echevarría, Roberto. Humanismo, retórica y las crónicas de la conquista. Historia y ficción en la narrativa hispanoamericana, Caracas, Monte Ávila, 1984.

GRUZINSKI, Serge. La colonización de lo imaginario. Sociedades indígenas y occidentalización en el México español siglos XVI-XVIII, México, Fondo de Cultura Económica, 1991.

MARTÍNEZ, José Luis. Conquista y contraconquista, la escritura del Nuevo Mundo: Actas del XXVIII Congreso del Instituto Internacional de Literatura Iberoamericana, Julio Ortega, José Amor y Vázquez, Rafael Olea Franco (coords.), pp. 149-158, 1994.

MILLARES Carlo, Agustín. Cuatro estudios biobibliográficos mexicanos: Francisco Cervantes de Salazar, fray Agustín Dávila Padilla, Juan José de Eguiara y Eguren, José Mariano Beristáin de Souza. México. Fondo de Cultura Económica, 1986.

\section{Marina Garone Gravier}

Doctora en Historia del Arte

https://orcid.org/0000-0002-5981-9243 •mgarone@unam.mx 